\title{
ANALISIS EFEKTIVITAS PELAKSANAAN KEBIJAKAN TAX AMNESTY (STUDI KASUS PADA KANTOR PELAYANAN PAJAK PRATAMA SUMBAWA BESAR)
}

\author{
Oleh : \\ Nurjanah \\ Fakultas Ekonomi dan Bisnis, Jurusan Akuntansi \\ Universitas Teknologi Sumbawa \\ e-mail : \\ Nurjanahapriatna@gmail.com
}

\begin{abstract}
Abstrak : Amnesti Pajak (Pengampunan Pajak) adalah suatu penghapusan pajak yang sebenarnya terutang, tanpa dikenakan sanksi administrasi perpajakan dan sanksi pidana dibidang perpajakan. Tujuan pemerintah membuat kebijakan Amnesti Pajak ini adalah untuk merepatriasi harta dari Wajib Pajak yang belum dilaporkan dalam SPT sebelumnya serta untuk merestrukturisasi objek pajak. Dimana kebijakan Amnesti Pajak ini didorong oleh semakin kecilnya kemungkinan Wajib Pajak untuk menyembunyikan kekayaannya diluar wilayah Negara Kesatuan Republik Indonesia. Tujuan penelitian ini adalah untuk mengetahui tingkat efektivitas penerapan Tax Amnesty (Pengampunan Pajak) terhadap penerimaan pajak pada Kantor Pelayanan Pajak Pratama Sumbawa Besar. Metode analisis data yang digunakan adalah deskriptif untuk menggambarkan prosedur Amnesti Pajak dan analisis kualitatif untuk menunjukan tingkat efektivitas penerapan Amnesti Pajak. Hasil penelitian menunjukan bahwa efektivitas pelaksanaan kebijakan tax amnesty pada Kantor Pelayanan Pajak Pratama Sumbawa Besar berada pada tingkat efektif.
\end{abstract}

Kata Kunci : Efektivitas, Pajak, Tax Amnesty 


\begin{abstract}
Tax Amnesty (Tax Forgiveness) is the elimination of actual tax payable, without being subject to tax administration sanctions and criminal sanctions in the field of taxation. The purpose of the government to make this tax amnesty policy is to repatriate the assets of taxpayers who have not been reported in the previous tax return and to restructure the tax object. Where the tax amnesty policy is driven by the smaller possibility of taxpayers to hide their wealth outside the territory of the Unitary State of the Republic of Indonesia. The purpose of this study was to determine the effectiveness of the implementation of the Tax Amnesty on tax receipts at the Sumbawa Besar Pratama Tax Office. The data analysis method used is descriptive to describe the Tax Amnesty procedure and qualitative analysis to show the level of effectiveness of the implementation of the Tax Amnesty. The results of the study show that the effectiveness of implementing the tax amnesty policy at the Sumbawa Besar Pratama Tax Office is at an effective level
\end{abstract}

Keyword : effectiveness, Tax, Tax Amnesty

\title{
Latar Belakang
}

\section{PENDAHULUAN}

Undang-Undang Nomor 28 pasal 1 ayat 1 tahun 2007 tentang Ketentuan Umum dan Tata Cara Perpajakan menyatakan bahwa, pajak merupakan iuran kepada kas negara berdasarkan UndangUndang yang dapat dipaksakan dengan tidak mendapat jasa timbal (kontraprestasi), yang langsung dapat ditujukan dan yang digunakan untuk membayar pengeluaran umum. Di Indonesia, pajak merupakan sumber penerimaan terbesar negara. Hal ini sangat wajar ketika sumber daya alam, khususnya minyak bumi tidak bisa diharapkan lagi. Penerimaan dari sumber daya alam memiliki umur yang terbatas, suatu saat akan habis dan tidak bisa diperbaharui. Berbeda dengan pajak yang mempunyai umur tidak terbatas, dengan melihat semakin bertambahnya jumlah penduduk.

Pada tahun 2016, pemerintah membuat kebijakan dalam upaya untuk mendorong penerimaan negara dengan mengusulkan kebijakan tax amnesty. Menurut Undang-Undang pengampunan pajak No.11 tahun 2016 tax amnesty adalah program pengampunan yang diberikan oleh pemerintah kepada wajib pajak meliputi penghapusan pajak terutang, penghapusan sanksi administrasi perpajakan, serta penghapusan sanksi pidana di bidang perpajakan atas harta yang 
diperoleh pada tahun 2015 dan sebelumnya yang belum dilaporkan dalam surat pemberitahuan (SPT).

Di kota Sumbawa Besar, Tax Amnesty (Pengampunan Pajak) adalah salah satu kebijakan yang diharapkan mampu menaikkan realisasi penerimaan pajak ditahun 2016 dan menaikkan tingkat kesadaran Wajib Pajak akan pentingnya membayar pajak bagi kemandirian dan kesejahteraan Negara. Menurut Staf sub. Bagian Umum dan Kepatuhan Internal pada KPP Pratama Sumbawa Besar, dalam pelaksanaan kebijakan Tax Amnesty (Pengampunan pajak), semua wajib pajak yang bermasalah menjadi target utama, karena masih banyak wajib pajak yang terdaftar pada KPP Pratama Sumbawa Besar yang kurang memiliki kesadaran dalam membayar kewajiban pajaknya. Mengingat wajib pajak ini sangat besar partisipasinya dalam membayar pajak sangat diharapkan dapat berpengaruh signifikan terhadap realisasi penerimaan pajak.

\section{Tujuan Penelitian}

1. Menganalisis tingkat efektivitas tax amnesty terhadap peningkatan penerimaan pajak pada Kantor Pelayanan Pajak Pratama Sumbawa Besar.

2. Menganalisis tingkat efektivitas tax amnesty terhadap peningkatan kepatuhan wajib pajak pada Kantor Pelayanan Pajak Pratama Sumbawa Besar.

3. Menganalisis tingkat efektivitas tax amnesty terhadap peningkatan jumlah wajib pajak pada Kantor Pelayanan Pajak Pratama Sumbawa Besar. 


\title{
TINJAUAN PUSTAKA
}

\section{Pajak}

Menurut Undang-Undang No. 28 Tahun 2007 pasal 1 ayat 1 pajak adalah kontribusi wajib kepada negara yang terutang oleh orang pribadi atau badan yang bersifat memaksa berdasarkan UndangUndang, dengan tidak mendapatkan imbalan secara langsung dan digunakan untuk keperluan negara bagi sebesar-besarnya kemakmuran rakyat.

\begin{abstract}
Akuntansi Pajak
Akuntansi Pajak menurut Waluyo (2014 : 35) adalah sebagai berikut: "Dalam menetapkan besarnya pajak terhutang tetap mendasarkan laporan keuangan yang disusun oleh perusahaan, mengingat tentang perundang undangan perpajakan terdapat aturan-aturan khusus yang berkaitan dengan akuntansi, yaitu masalah konsep transaksi dan peristiwa keuangan, metode pengukurannya, serta pelaporan yang ditetapkan dengan undangundang."
\end{abstract}

\section{Sanksi Perpajakan}

Sanksi perpajakan merupakan jaminan bahwa ketentuan peraturan perundang-undangan perpajakan akan di patuhi. Dengan kata lain sanksi perpajakan merupakan alat pencegahan agar wajib pajak tidak melanggar norma perpajakan (Mardiasmo, 2016:62).

\section{Tax Amnesty (pengampunan pajak)}

Menurut "PMK No.11/PMK.03/2016" tax amnesty adalah penghapusan pajak yang seharusnya terutang, tidak dikenai sanksi administrasi perpajakan dan sanksi pidana di bidang perpajakan, dengan cara mengungkap Harta dan membayar Uang Tebusan sebagaimana diatur dalam Undang-Undang Pengampunan Pajak. Tarif uang tebusan yang hartanya dialihkan ke dalam wilayah NKRI berdasarkan "PMK No.118/PMK.03/2016" adalah sebesar :

1. $2 \%$ untuk penyampaian surat pernyataan pada periode pertama yaitu dari (1 Juli 2016 - 30 September)

2. 3\% untuk penyampaian surat pernyataan pada periode kedua yaitu dari (1 Oktober 2016 - 31 Desember 2016) 
3. $5 \%$ untuk penyampaian surat pernyataan pada periode ketiga yaitu dari (1 Januari 2017 - 31 Maret 2017)

Sedangkan untuk tarif uang tebusan yang hartanya tidak dialihkan kedalam wilayah NKRI berdasarkan "PMK No.118/PMK.03/2016" adalah sebesar :

1. $4 \%$ untuk penyampaian surat pernyataan pada periode pertama yaitu dari (1 Juli 2016 - 30 September 2016)

2. $6 \%$ untuk penyampaian surat pernyataan pada periode kedua yaitu dari (1 Oktober 2016 - 31 Desember 2016)

3. $10 \%$ untuk penyampaian surat pernyataan pada periode ketiga yaitu dari (1 Januari 2017 - 31 Maret 2017)

Dan untuk tarif uang tebusan bagi wajib pajak yang peredaran usahanya sampai dengan Rp 4.800.000.000 (empat miliar delapan ratus juta) pada tahun pajak terakhir berdasarkan "PMK No.118/PMK.03/2016" adalah sebesar :

1. $0,5 \%$ bagi wajib pajak yang mengungkapkan nilai harta sampai dengan Rp 10.000.000.000 dalam surat pernyataan; atau

2. $2 \%$ bagi wajib pajak yang mengungkapkan nilai harta lebih dari $\mathrm{Rp} \mathrm{10.000.000.000} \mathrm{dalam} \mathrm{surat} \mathrm{pernyataan}$

\section{Efektivitas}

Agung Kurniawan (2005:109) menjelaskan jika efektivitas merupakan kemampuan melaksanakan tugas, fungsi (operasi kegiatan program atau misi) dari pada suatu organisasi atau sejenisnya yang tidak adanya tekanan atau ketegangan diantara pelaksanaannya. Efektivitas menurut Mardiasmo (2009:132) pada dasarnya berhubungan dengan pencapaian tujuan atau target kebijakan (hasil guna). Efektivitas merupakan hubungan antara keluaran dengan tujuan atau sasaran yang harus dicapai.

\section{Penelitian Terdahulu}

M.A.Awaeh 2017 Analisis Efektivitas Penerapan Tax Amnesty (Pengampunan Pajak) Terhadap Penerimaan Pajak Pada Kantor Pelayanan Pajak Pratama Bitung. Hasil penelitian menunjukan bahwa penerapan efektivitas Amnesti Pajak pada periode pertama sebesar $77,94 \%$ dan penurunan yang sangat signifikan terjadi pada periode kedua sebesar $22,27 \%$ atau mengalami penurunan sebesar $55,65 \%$ sehingga dikatakan tidak efektif. Hal ini dikarenakan 
program Amnesti Pajak hanya dapat mengambil 4,24\% bagian dalam penerimaan pajak pada KPP Pratama Bitung.

C.A.Kartika 2017 Analisis Efektivitas Penerapan Tax Amnesty (Pengampunan Pajak) Terhadap Penerimaan Pajak Dari Wajib Pajak Badan Usaha Pada Kantor Pelayanan Pajak Pratama Manado. Hasil penelitian menunjukkan bahwa penerapan tax amnesty periode pertama sudah sangat efektif, namun berbeda pada periode kedua yang mengalami penurunan sangat signifikan sehingga tergolong tidak efektif, penyebabnya adalah sebagian besar wajib pajak sudah berpartisipasi pada periode pertama.

\section{METODE PENELITIAN}

\section{Jenis Penelitian}

Jenis penelitian yang digunakan oleh penulis adalah kualitatif deskriptif. Menurut Anshori dan Iswati (2006:13) penelitian deskriptif adalah penelitian yang dilakukan untuk mengetahui tentang variabel mandiri, baik satu variabel atau lebih. Menurut Sugiyono (2010:9) penelitian kualitatif adalah suatu metode penelitian yang berlandaskan pada filsafat postpositivisme, digunakan untuk meneliti pada kondisi objek yang alamiah dimana peneliti adalah sebagai instrumen kunci, teknik pengumpulan data dilakukan secara triangulasi (gabungan), analisis data bersifat induktif/kualitatif, dan hasil penelitian kualitatif lebih menekankan makna dari pada generalisasi.

\section{Lokasi Penelitian}

Lokasi penelitian yang digunakan oleh penulis dalam penelitian ini yaitu Kantor Pelayanan Pajak Pratama Sumbawa Besar yang beralamat di Jl.garuda no. 70-72 Kabupaten Sumbawa, Nusa Tenggara Barat.

\section{Sumber Data}

Dalam penelitian ini, peneliti menggunakan jenis data dari sumber primer dan sumber sekunder:

1. Sumber Primer 
Menurut Sugiyono (2010 : 225) Data primer adalah data yang diberikan secara langsung kepada pengumpul data.

2. Sumber Sekunder data sekunder menurut Sugiyono (2010 : 225) adalah data yang tidak langsung diberikan kepada pengumpul data, misalnya lewat orang lain atau lewat dokumen.

\section{Teknik Pengumpulan Data}

Teknik pengumpulan data dalam penelitian ini yaitu sebagai berikut:

1. Wawancara, Menurut Esterberg dalam Sugiyono (2010 : 231) wawancara merupakan pertemuan dua orang untuk bertukar informasi dan ide melalui tanya jawab, sehingga dapat dikontruksikan makna dalam suatu topik tertentu.

2. Observasi, Sutrisno Hadi, dalam Sugiyono (2010 : 145) mengemukakan bahwa, observasi merupakan suatu proses yang kompleks, suatu proses yang tersusun dari berbagai proses biologis dan psikologis. Dua diantara yang terpenting adalah proses-proses pengamatan dan ingatan.

3. Dokumentasi, Sugiyono (2010 : 240) dokumen merupakan catatan peristiwa yang sudah berlalu. Dokumen bisa berbentuk tulisan, gambar, atau karya-karya monumental dari seseorang.

\section{Teknik Analisa Data}

Teknik Analisa yang digunakan peneliti adalah:

1. Pengumpulan Data

2. Reduksi data

3. Penyajian data

4. Analisa data

5. Uji keabsahan data

6. Kesimpulan 


\section{Hasil Penelitian dan Pembahasan}

\section{Pengukuran efektivitas tax amnesty terhadap peningkatan penerimaan pajak.}

Analisis efektivitas penerapan Tax Amnesty terhadap penerimaan pajak dapat dilihat pada tabel berikut ini:

Rasio Efektivitas Tax Amnesty Terhadap Penerimaan Pajak

Pada Tahun 2016 dan 2017

\begin{tabular}{|c|c|c|c|c|}
\hline Tahun & Periode & $\begin{array}{c}\text { Realisasi tax } \\
\text { amnesty }\end{array}$ & Realisasi pajak & Presentase \\
\hline 2016 & 1 dan 2 & Rp 13.495.414.551 & $\operatorname{Rp~580.424.863.321~}$ & $2,3 \%$ \\
\hline 2017 & 3 & $R p 3.579 .923 .213$ & $\operatorname{Rp~519.291.606.003~}$ & $0,68 \%$ \\
\hline
\end{tabular}

Dari hasil perbandingan realisasi penerimaan tax amnesty periode pertama dan kedua dengan realisasi penerimaan pajak tahun 2016, jumlah presentase yang diperoleh sebesar 2,3\% sehingga dikategorikan "tidak efektif". Tidak efektifnya penerimaan tax amnesty terhadap penerimaan pajak ini dapat dilihat dari jumlah realisasi penerimaan tax amnesty selama dua periode berjalan yaitu hanya sebesar $\mathrm{Rp}$ 13.495.414.551 atau belum efektif terhadap kenaikan penerimaan pajak pada Kantor Pelayanan Pajak Pratama Sumbawa Besar.

Begitu pula dengan hasil perbandingan realisasi penerimaan tax amnesty periode ketiga dengan realisasi penerimaan pajak pada tahun 2017, dapat diketahui terdapat presentase sebesar 0,68\% sehingga di kategorikan "tidak efektif". Tidak efektifnya penerimaan tax amnesty terhadap penerimaan pajak ini dapat dilihat dari jumlah realisasi penerimaan tax amnesty periode ketiga yang sangat menurun dibandingkan periode-periode sebelumnya yaitu sebesar Rp 3.579.923.213.

\section{Pengukuran efektivitas tax amnesty terhadap peningkatan jumlah wajib pajak.}

Pengukuran efektivitas tax amnesty terhadap peningkatan jumlah wajib pajak dapat dilihat dari selisih peningkatan jumlah wajib pajak setiap tahunnya. 
Data Jumlah Wajib Pajak

Sebelum dan Sesudah Tax Amnesty

\begin{tabular}{|c|c|c|c|c|}
\hline Tahun & Banyak Wajib Pajak & Selisih & Persentase & Keterangan \\
\hline 2015 & 53.846 & & & \\
\hline 2016 & 59.707 & 5.861 & $10,88 \%$ & Naik \\
\hline 2017 & 64.384 & 4.677 & $0,78 \%$ & Naik \\
\hline 2018 & 74.078 & 9.694 & $15 \%$ & Naik \\
\hline
\end{tabular}

Berdasarkan hasil analisis diatas dapat disimpulkan bahwa pelaksanaan kebijakan tax amnesty terhadap peningkatan jumlah wajib pajak dapat dikatakan efektif, hal ini sesuai dengan hasil analisis data yang menunjukan adanya peningkatan jumlah wajib pajak setelah tax amnesty dilaksanakan.

3. Pengukuran efektivitas pelaksanaa kebijakan tax amnesty terhadap peningkatan kepatuhan wajib pajak dalam melapor.

Pengukuran efektivitas pelaksanaan kebijakan tax amnesty terhadap peningkatan kepatuhan wajib pajak dalam melapor dapat dilihat dari hasil perbandingan realisasi dan target kepatuhan wajib pajak setiap tahunnya dari tahun 2015, 2016, 2017 dan 2018.

Data Tingkat Kepatuhan Wajib Pajak Dalam Melapor

\begin{tabular}{|l|l|l|l|}
\hline Tahun & Target & Realisasi & Keterangan \\
\hline 2015 & $41,00 \%$ & $44,93 \%$ & Efektif \\
\hline 2016 & $67,50 \%$ & $68,12 \%$ & Efektif \\
\hline 2017 & $50,00 \%$ & $51,72 \%$ & Efektif \\
\hline 2018 & $50,00 \%$ & $61,32 \%$ & Efektif \\
\hline
\end{tabular}

Berdasarkan hasil analisis diatas dapat disimpulkan bahwa efektivitas pelaksanaan kebijakan tax amnesty dalam meningkatkan tingkat kepatuhan wajib pajak dalam melapor berada pada kategori efektif yang dimana dapat dilihat dari 
perbandingan target dan realisasi tax amnesty yang setiap tahunnya mengalami kenaikan atau melebihi target yang ditetapkan oleh Kantor Pelayanan Pajak Pratama Sumbawa Besar.

\section{PENUTUP}

\section{KESIMPULAN}

Berdasarkan hasil dari analisis data terhadap pengukuran tingkat efektivitas penerimaan tax amnesty setiap periode, dapat disimpulkan bahwa tingkat efektivitas tax amnesty pada periode pertama sampai periode ketiga sudah efektif dengan tingkat efektivitas sebesar 100\%, akan tetapi dalam tujuannya yaitu menaikkan penerimaan pajak penerapan kebijakan tax amnesty di KPP Pratama Sumbawa Besar ini belum mampu mencapai tujuan. Hal ini sebagimana sesuai dengan hasil analisis efektivitas tax amnesty terhadap penerimaan pajak pada tahun 2016 sebesar 2,3\% dan pada tahun 2017 sebesar 0,68\%. Maka berdasarkan analisis tersebut penerapan kebijakan tax amnesty pada Kantor Pelayanan Pajak Pratama Sumbawa Besar belum mampu mendongkrak atau menaikkan penerimaan pajak secara signifikan.Dan hasil analisis efektivitas pelaksanaan kebijakan tax amnesty terhadap peningkatan jumlah wajib pajak, dan peningkatan kepatuhan wajib pajak dalam melapor dapat dikatakan efektif. Hal ini sesuai dengan hasil analisis dan data yang di dapatkan bahwa terdapat kenaikan jumlah wajib pajak setiap tahunnya, dan terdapat kenaikan pada tingkat kepatuhan wajib pajak dalam melapor yang setiap tahunnya melebihi dari angka target yang telah ditetapkan oleh Kantor Pelayanan Pajak Pratama Sumbawa Besar.

\section{Saran}

Kantor Pelayanan Pajak Pratama Sumbawa Besar telah melakukan pelaksanaan kebijakan tax amnesty dengan baik akan tetapi masih ada proses yang belum maksimal yaitu tidak adanya target dalam penerimaan tax amnesty, diharapkan Kantor Pelayanan Pajak Pratama Sumbawa Besar mempunyai target dalam setiap kebijakan yang ada, hal ini penting dikarenakan target merupakan sebuah motivasi capaian yang harus dicapai agar kebijakan tersebut lebih baik dan bermanfaat sesuai tujuannya. 


\section{DAFTAR PUSTAKA}

Agung, Kurniawan (2005). Transformasi Pelayanan Publik.Yogyakarta: Pembaharuan.

Agoes, Sukrisno. (2014). Auditing Petunjuk Praktis Pemeriksaan Akuntan oleh. Akuntan Publik. Edisi ke 4. Buku 1. Jakarta: Salemba Empat

Anshori, M., \& Iswati, S. (2006). Metodologi Penelitian Kuantitatif. Surabaya: Airlangga University Press.

Huslin, D. (2015). Pengaruh Sunset Policy, Tax Amnesty, dan Sanksi Pajak terhadap Kepatuhan Wajib Pajak (Studi Empiris di Kantor Pelayanan Pajak Pratama Jakarta Kembangan).

Keputusan Menteri Dalam Negeri No.690.900.327 Tahun 1996 tentang

Mardiasmo, (2009). Akuntansi Sektor Publik, Yogyakarta: Penerbit Andi.

Mardiasmo, (2016). Perpajakan. Edisi Revisi. Yogyakarta: Andi.

Mujiyati dan A. Aris. (2010). Perpajakan. Surakarta:Muhammadiyah UniversityPress.

Muryanti, Kiky. (2017). "Analisis Realisasi Anggaran Untuk Menilai Efektivitas dan Efisiensi Kinerja Pemerintah Daerah Kabupaten Wonogiri Tahun Anggaran 2011-2015”. Skripsi. Surakarta: Program Studi Akuntansi Fakultas Ekonomi Dan Bisnis Universitas Muhammadiyah Surakarta.

Peraturan Menteri Keuangan Nomor 11 tahun 2016 tentang pengampunan pajak.

Rondonuwu, R. H., Tinangon, J. J. \& N. Budiarso. (2015). "Analisis Efisiensi dan Efektivitas Pengelolaan Keuangan Daerah Pada Dinas Pendapatan Daerah Kabupaten Minahasa". Jurnal EMBA, 3(4), 23-32.

Sugiyono. (2010). Metode Penelitian Pendidikan Pendekatan Kuantitatif, kualitatif,

dan R\&D. Bandung: Alfabeta.

Suryarini, T dan S, Anwar. (2010). Dampak Kebijakan Sunset Policy Terhadap Kemauan Membayar Pajak Pada Kpp Semarang Barat. Jurnal Dinamika Akuntansi, Vol. 2, No. 2, hal 135-146.

Undang-Undang, Republik Indonesia. Nomor 28 tahun 2007 tentang Ketentuan Umum dan Tata Cara Perpajakan 
Undang-Undang, Republik Indonesia Nomor 11 tahun 2016 tentang Pengampunan Pajak

Valeyati, (2013). Analisis Efektivitas dan Kontribusi Tindakan

Penagihan Pajak Aktif Dengan Surat Teguran Dan

Surat Paksa Sebagai Upayah Pencairan Tunggakan

Pajak (Studi pada Kantor Pelayanan Pajak Pratama

Batu Tahun 2010-2012). Jurnal Universitas Brawijaya.

Waluyo, (2014). Perpajakan Indonesia.Jakarta : Salemba Empat.

Widayati dan Nurlis. (2010). Faktor - Faktor yang Mempengaruhi

Kemauan Membayar Pajak Wajib Pajak Orang Pribadi yang Melakukan Pakerjaan Bebas. Makalah Simposium Nasional Akuntansi XIII Purwokerto. 